Paper 5. Tuu, H. H. \& Olsen, S. O. Certainty, risk and knowledge in the satisfaction-purchase intention relationship in a new product experiment. Submitted to Asia Pacific

Journal of Marketing and Logistics. 



\section{Emerald $\begin{aligned} & \text { Asia Pacific Journal of } \\ & \text { Marketing and Logistics }\end{aligned}$}

\section{Certainty, risk and knowledge in the satisfaction-purchase intention relationship in a new product experiment}

\begin{tabular}{|r|l|}
\hline Journal: & Asia Pacific Journal of Marketing and Logistics \\
\hline Manuscript ID: & Draft \\
\hline Manuscript Type: & Research Paper \\
\hline Keywords: & Satisfaction, purchase intention, certainty, risk, knowledge \\
\hline \multicolumn{2}{|l}{} \\
\hline
\end{tabular}

\section{SCHOLARONE ${ }^{\text {th }}$ \\ Manuscripts}




\title{
Certainty, risk and knowledge in the satisfaction-purchase intention relationship in a new product experiment
}

\begin{abstract}
Purpose - This study examines the roles of perceived certainty, manipulated risk and knowledge in the satisfaction-purchase intention relationship in a context of a new product evaluation.

Design / methodology / approach - This study uses a 2 x 2 factorial design with 120 participants and a combination of methods to test hypotheses.

Findings - The findings indicate that satisfaction is not different between the respondents in high- versus low-risk groups and in high- versus low-knowledge groups. However, the respondents of low-risk as well as high-knowledge groups report a higher purchase intention. Interestingly, the movement from satisfaction to purchase intention is higher among the respondents with higher certainty, and among the respondents in low-risk as well as highknowledge groups. Furthermore, in the conditions of low-manipulated knowledge, higher manipulated risk leads to a significantly lower consistence between satisfaction and purchase intention. By contrast, in the conditions of high-manipulated knowledge, the decease in the consistence between satisfaction and purchase intention is not significant. Thus, the results reveal that manipulated knowledge reduces the negative moderator effect of manipulated risk on the satisfaction-purchase intention relationship.

Research limitations / implications - This study uses only one new food product, thus future studies should use an experimental design with a variety of new different products, brands and services to gain a more comprehensive understanding of the formation of purchase intentions. Both product risk and consumer knowledge consist of multidimensional constructs, thus it will be interesting for future studies to manipulate each of the facets of product risk (e.g., financial risk)
\end{abstract}


and knowledge (e.g., procedural knowledge) to explore their effects on consumer satisfaction and purchase intentions as well as the relationship between these two constructs.

Practical implications - Our findings suggest that managers should be aware of satisfaction strength and risk in their estimation of purchase intention based on satisfaction measurement. Marketing strategies, which reduce consumers' risks, consolidate their confidence and educate them with relevant knowledge, may be effective strategies to increase their purchase intention, especially towards new products.

Originality / Value - This is, to our knowledge, the first study to examine simultaneously the different roles of perceived certainty, manipulated risk and knowledge within a satisfactionpurchase intention relationship. It is also the first to provide empirical evidence supporting an interaction between knowledge and risk affecting the satisfaction-purchase intention relationship. Finally, it uses a controlled experiment in the context of a new product evaluation to confirm causal effects.

Keywords: Satisfaction, intention, certainty, risk, knowledge, experiment, new product. 


\section{Introduction}

Purchase intention is an important concept studied in the marketing literature (Johnson et al., 2006; Oliver, 1997). Marketing managers are interested in consumers' purchase intention in order to forecast sales of existing and/or new products and services as well as to aid marketing decisions related to the product demand for new and existing products, market segmentation and promotional strategies (Tsiotsou, 2006). The forming of consumers' purchase intention should be particularly dynamic (Oliver, 1997), especially for a new-to-market offering (Johnson et al., 2006). In this early stage of a product, satisfaction is suggested to have a direct influence on purchase intention (Johnson et al., 2006; Marzursky and Geva, 1989). Furthermore, previous studies also suggests that the relationship between satisfaction and purchase intention is affected by moderators such as consumer or situational characteristics (Evanschitzky and Wunderlich, 2006; Walsh et al., 2008). However, only a few studies that we know of explore moderators in the satisfaction-purchase intention relationship in the context of a new product (e.g., Marzursky and Geva, 1989; Smith and Swinyard, 1983).

Certainty, product risk and knowledge are found as the important predictors of attitude/satisfaction and purchase intention/behavior as well as the moderators in the relationship between these two constructs (Berger, 1992; Capraro et al., 2003; Evanschitzky and Wunderlich, 2006; Gurhan-Canli and Batra, 2004; Tuu and Olsen, 2009). However, most of these studies are in the area of established brands, products, and services, and designed as cross sectional selfadministrated surveys. Thus, this study extends to provide a deeper understanding about the different roles (e.g., moderator effects) of certainty, product risk, and knowledge by investigating these variables in a controlled experiment framed in a study of satisfaction and purchase intention in the context of a new product evaluation. This context is noteworthy because consumers' 
satisfaction with a new product may often be marked by uncertainty, biased evaluations (Berger et al., 1994), the potential risks of the product (DelVecchio and Smith, 2005; Heilman et al., 2000; Roe and Teisl, 2007) and knowledge and information that has been presented in the context of the tried or new products (Marzursky and Geva, 1989).

Therefore, this study is expected to be interesting not only by providing an insight into the formation of purchase intention, but also by providing implications for developing new insights into the dynamics of new-product evaluation where all consumers have the same possibility to evaluate relevant product attributes. This is important because the ratio of failures in marketing new products is reported as being up to $75 \%$ (Cooper and Kleinschmidt, 1987; 1991).

Furthermore, an understanding of new product success factors is important because it provides guidelines for the screening of new products as well as leading to insights into the way the new product projects should be managed (Cooper and Kleinschmidt, 1987). It also has important implications for labeling as well as providing practical guidelines for the safe use of new products, especially when the perceptions of risks are always presented (Martinez-Poveda et al., 2009; Roe and Teisl, 2007). In the next parts, the hypotheses are developed, then an experimental design is described and finally the hypotheses are tested.

\section{Theoretical framework}

\section{Satisfaction and purchase intention}

Satisfaction is the consumer's fulfillment response, the degree to which the level of fulfillment is pleasant or unpleasant (Oliver, 1997). Johnson, Nader, and Fornell (1996) describe two basic conceptualizations of satisfaction, transaction-specific and cumulative. Transaction-specific satisfaction is a customer's transient evaluation of a particular product or service experience, 
while cumulative satisfaction describes the total consumption experience of a product to date. In this study, satisfaction is defined as positive affective responses as the consequences of the fulfilment of an individual's expectance about a product in a specific transaction (Johnson et al., 1996; Oliver, 1997).

Purchase intention is considered as a mediator between satisfaction and actual loyalty (Evanschitzky and Wunderlich, 2006; Oliver, 1999), and differs from repurchase behavior (Mittal and Kamakura, 2001). Because this study evaluates a new product in a trial stage, purchase intention is defined as the expectance and the probability of buying a new product given a reference price in a time-specific frame. A positive association between satisfaction and purchase intention relationship is well established in the literature (Johnson et al., 2006; Marzursky and Geva, 1989; Szymanski and Henard, 2001; Walsh et al., 2008). Thus, the following hypothesis is suggested:

H1: Satisfaction has a positive effect on purchase intention.

However, with the same level of satisfaction reported, purchase intention is found to vary between products, industries, and situations (Szymanski and Henard, 2001), which means that the effect of satisfaction on purchase intention may be affected by moderators (Baron and Kenny, 1986; Evanschitzky and Wunderlich, 2006; Seiders et al., 2005). Thus, we want to investigate the different roles of perceived certainty and manipulated risk and knowledge with a more focus on their moderator effects on the satisfaction-purchase intention relationship.

\section{Perceived certainty}

Certainty refers to the amount of exactness or confidence a person attaches to an attitude (Olsen, 1999). Certainty has been described as an evaluative mechanism by which consumers assess 
whether individuals' beliefs about brands and alternatives are accurate or correct (Dick and Basu, 1994). More recently, certainty is defined as the sense of conviction with which the satisfaction judgement is held in a specific transaction (Chandrashekaran et al., 2007).

Previous studies indicate that perceived certainty may enhance (re)purchase intention (Bauer, 1960; Bennett and Harrell, 1975; Laroche et al., 1996). Consumers with more perceived certainty will believe not only that the favourable outcome (i.e., satisfaction) should be ascribed to their own action, but also that the cause of a prior favourable outcome will endure in the future (Campbell et al., 2004). From this perspective, perceived certainty may play a role as a predictor of purchase intention as well as a positive moderator of the effect of satisfaction on purchase intention. Consumers with higher perceived certainty in their evaluations of products should confirm higher attitude-buying behaviour relationship (see Olsen, 1999 for a theoretical discussion). The positive moderator role of certainty in the satisfaction-purchase intention relationship means that customers who hold certain feelings of satisfaction about the product exhibit a stronger satisfaction-purchase intention relationship than customers with uncertainty feelings (Chandrashekaran et al., 2007). It means that with the same level of satisfaction consumers with more perceived certainty will have a higher purchase intention than those with less perceived certainty in evaluations of satisfaction.

H2: $\quad$ Perceived certainty (a) has a positive effect on purchase intention and (b) moderates positively the satisfaction-purchase intention relationship.

\section{Product risks}

Perceived risk can be evaluated for both pre- and post-purchase (Grewal et al., 2007) involving consumer perceptions of negative consequences and losses associated with consuming a 
particular product (Dowling and Staelin, 1994). Generally, perceived risk is considered as a multidimensional construct (Jacoby and Kaplan, 1972; Yuksel and Yuksel, 2007). In this study, manipulated risk is defined as the pre-purchase risky information about unfavourable potential consequences and losses in the process of evaluating and consuming a product (Dowling and Staelin, 1994; Grewal et al., 2007). When potential outcomes are perceived more negatively, the level of perceived risk associated with the purchase will increase (DelVecchio and Smith, 2005).

A few studies using survey data suggest that perceived risk has a negative association with consumers' cumulative satisfaction or evaluation (Chen and Li, 2007; Pires et al., 2006; Tuu and Olsen, 2009; Yuksel and Yuksel, 2007). However, the empirical evidence on this issue is not consistent, suggesting both a weak and/or a non-significant effect of perceived risk on cumulative satisfaction or attitude evaluation. For example, Yuksel and Yuksel (2007) did not find any direct association between perceived risk and satisfaction, but an indirect association through negative emotional reactions about states of pleasure and arousal of customers. Perceived risk is found to have a very weak negative effect on attitude (Chen and Li, 2007). Pires et al., (2006) find a negative association between perceived risk and satisfaction only for low involvement products. However, because perceived risk often reduces the perceived benefits of a product (Alhakami and Slovic, 1994; Saba and Messina, 2002), perceived risk may lead consumers to dissatisfaction. According to Bauer (1960), consumers' purchasing actions in highly risky situations will produce unanticipated uncertainty consequences, at least some of which are likely to be unpleasant. Furthermore, it is possible to argue that consumers who receive highly risky information about a (new) product will reduce their expectances of the product, which in turn may lead to a lower level of satisfaction (Oliver, 1980; Spreng et al., 1996). Because the association between perceived risk and satisfaction in a specific transaction is still uncovered, it is worthwhile testing a negative effect of manipulated risk on transaction-specific satisfaction. 
Previous research also provides strong evidence that perceived risk has a negatively direct effect on purchase and (re)purchase intention (Grewal et al., 2007; Mitchell et al., 1999; Tsiros and Heilman, 2005; Yuksel and Yuksel, 2007). However, most of those studies investigate the postpurchase behaviours of consumers. Thus, perceived risk is considered as the probability distribution of uncertain outcomes after a purchase, which is called postpurchase perceived risk (Grewal et al., 2007). In other words, postpurchase perceived risk is the consumers' belief about the probability that they might suffer negative consequences from initially purchasing a specific good or service (Bauer, 1960; Grewal et al., 2007). Although it is suggested that research on prepurchase perceived risk for products can lend some credence to the contention that postpurchase perceived risk will affect purchase intentions (Grewal et al., 2007), only a little evidence is provided (Alhakami and Slovic, 1994; Dowling, 1986). Because in a specific transaction consumers are often motivated to avoid negative experiences rather than to maximize utility (Lim, 2003), we expect that when consumers receive and integrate highly risky information into the consideration process, the probability that they will purchase the product will be low.

Overall perceived risk is found to moderate negatively the attitude-behaviour relationship in a few studies (Campbell and Goldstein, 2001; Gurhan-Canli and Batra, 2004). Perceived risk often relates to losses and future uncertainty consequences (DelVecchio and Smith, 2005; Dowling and Staelin, 1994) as well as damaging perceived benefits as mentioned above (Alhakami and Slovic, 1994; Saba and Messina 2002). In addition, higher perceived risk inhibits exploratory tendencies and leads consumers to prefer familiar options to unfamiliar ones (Campbell and Goldstein, 2001), such as a new product. Thus, it is reasonable to anticipate that when consumers receive highly risky information about the (new) product, their expectations and then experienced satisfied feelings in a specific transaction are formed with less stability or less 
certainty (Bennett and Harrell, 1975), which will hinder the movement from satisfaction to purchase intention Chandrashekaran et al., 2007). Based on these above discussions, we suggest that:

H3: Higher manipulated risk (a) decreases satisfaction, (b) decreases purchase intention, (c) decreases certainty, and (d) moderates negatively the satisfaction-purchase intention relationship.

\section{Consumer knowledge}

Knowledge is mostly categorized as familiarity and expertise, in which familiarity is a function of product-related experiences that have been accumulated by the consumer whereas expertise is the ability to perform product-related tasks (Alba and Hutchinson, 1987). Another classification by psychologists distinguishes two key types of knowledge, declarative knowledge and procedural knowledge (Worsley, 2002). Knowledge is also classified according to its content, nature, complexity, valence and the amount of information stored in the memory (Fabrigar et al., 2006). In this study, manipulated knowledge is defined as the amount of product-relevant information about familiarity and expertise involving declarative and procedural understandings that consumers receive and use in the process of evaluating and consuming the product in a specific transaction (Alba and Hutchinson, 1987; Smith et al., 2008; Worsley, 2002).

Previous research indicates that knowledge can influence attitude, evaluation and consumption behaviours (Cordell, 1997; Rortveit and Olsen, 2007). Consumers with a higher level of knowledge can also realize a product or service's benefits better than those with a lower level of knowledge (Chen and $\mathrm{Li}, 2007$ ), thus knowledge is also suggested to influence cumulative satisfaction positively (Tuu and Olsen, 2009). In a specific transaction, consumers' overall satisfaction may result from their satisfaction with the product outcome itself and 
satisfaction with the information provided about the product (Spreng et al., 1996). The amount as well as the adequacy of information about a product can affect consumers' perceptions of key product characteristics, which will impact on their acceptance of the product (Roe and Teisl, 2007). Therefore, the more relevant and positive information consumers receive and use in the consideration process to consume a product, higher levels of their expectations and then their overall satisfaction with the product are predicted (Gardial et al., 1994; Spreng et al., 1996). Although to our knowledge no studies confirm an association between consumer knowledge and transaction-specific satisfaction, this study expects that higher manipulated knowledge will lead to a higher level of transaction-specific satisfaction.

Previous research also finds a positive relationship between perceived knowledge and consumption frequency (Rortveit and Olsen, 2007) and purchase intention (Soderlund, 2002). The consumers' cognitive mechanism and their perception of product properties are markedly affected by information (Caporate and Monteleon, 2004; Pieniak et al., 2007). Especially, consumers' knowledge about the product will increase when they receive more actual amounts of product-relevant information and think carefully about that information (Smith et al., 2008). Therefore, by providing information about a product, such as on the product label, consumers' purchase intention can be influenced (Pieniak et al., 2007). Based on these discussions, this study suggests that consumers with higher manipulated knowledge have a higher purchase intention than those with lower manipulated knowledge about the evaluative products.

Consumers with high knowledge process information more deeply in order to identify what is relevant and important (Alba and Hutchinson, 1987), thus knowledge is suggested as a moderator in the attitude-behaviour relationship (Fabrigar et al., 2006) as well as in the satisfactionpurchase intention relationship (Chiou et al., 2002). Higher perceived knowledge such as market expertise is often proposed to lead to a lower predictive power of satisfaction on its consequences 
including purchase intentions (Capraro et al., 2003; Evanschitzky and Wunderlich, 2006; Tuu and Olsen, 2009; Walsh et al., 2008). However, the moderator effect of knowledge in the satisfaction-purchase intention relationship may depend on the nature, amount, level, and content of knowledge (Fabrigar et al., 2006). Furthermore, as long as customers are satisfied, the strength of the satisfaction-purchase intention relationship is expected to be greater if satisfaction and intentions are formed under the central processing enabled by high knowledge (Chiou et al., 2002). One recent study by Fabrigar et al., 2006) indicates that consumers in the conditions of high relevant knowledge express a higher consistency between their attitudes and behaviours relative to those in the conditions of low relevant knowledge. In addition, higher manipulated knowledge is also suggested to generate higher certainty in evaluations of attitude/satisfaction (Smith et al., 2008), which in its turn increases the predictive power of satisfaction on its consequences, such as (re)purchase intention or loyalty (Chandrashekaran et al., 2007). Because consumers have especially lost confidence/certainty from a lack of knowledge or information about the new products (Martinez-Poveda et al., 2009), higher manipulated knowledge is expected to lead to higher consistence between satisfaction and purchase intention towards a new product than lower manipulated knowledge. Based on these above discussions, the hypothesis is as follows:

H4: Higher manipulated knowledge (a) increases satisfaction, (b) increases purchase intention, (c) increases certainty, and (d) moderates positively the satisfaction-purchase intention relationship.

\section{The interaction between knowledge and perceived product risk}

Because when consumers perceive high levels of perceived risk associated with product quality, they often rely on their knowledge and various sources of information to perform evaluations and 
buying decisions about the products (Chen and Li, 2007; Gurhan et al., 2004). In addition, consumers with a high level of knowledge or a high amount of relevant information often give evaluations more exactly and confidently than consumers with a low level of knowledge (Alba and Hutchison, 1987; Fabrigar et al., 2006; Smith et al., 2008). Therefore, except for the case of too highly perceived risk, which overcomes consumers' tolerance and then prevents them from making relevant exchanges (Yuksel and Yuksel, 2007), it is rational to expect that consumers with a higher level of knowledge have the ability to limit the negative consequences of risks better than those with a lower level of knowledge. In other words, the negative effects of perceived risk on its consequences (e.g., satisfaction, purchase intention, certainty as well as the satisfaction-purchase intention relationship) are weaker for higher knowledge consumers than for lower knowledge consumers. A few pieces of empirical evidence also indicate that knowledge can moderate negatively the relationships between cognitive constructs (e.g., perceived quality, perceived risk) and satisfaction/loyalty (Evanschizky and Wunderlich, 2005; Tuu and Olsen, 2009). Therefore, this study explores the interaction between manipulated knowledge and manipulated risk to influence satisfaction, purchase intention, certainty as well as the satisfaction-purchase intention relationship toward a new product, and suggests that:

H5: The deceases in satisfaction, purchase intention, certainty and the consistence of the satisfaction-purchase intention relationship due to higher manipulated risk are smaller among consumers in the conditions of higher manipulated knowledge than among consumers in the conditions of lower manipulated knowledge.

\section{Methods}

Product, participants, and procedures 
A canned mackerel product without a label and expiry date is used for the present study. It is common for canned fish products to be consumed in inland markets, while in Nhatrang, a coastal city in central Vietnam where this study was carried out, most people eat fresh fish; therefore, this product is expected to be unfamiliar and new to lots of people. In fact, at the time of the study, it was not available in Nhatrang.

A total of 120 students ( 80 females and 40 males) aged from 20 to 22 from the Economics Faculty, Nhatrang University, Vietnam volunteered to participate in this study. The data were collected with a questionnaire that included a scenario, which has been used extensively in satisfaction and purchase intentions (Soderlund, 2002). All participants were informed that this product was totally new and had not been presented in the market. Each participant was welcomed, asked to observe a 'new product. read a brief study description, and signed a consent form.

\section{Manipulations}

The experiment was a 2 (knowledge: low versus high) $\times 2$ (perceived risk: low vs. high) betweensubjects factorial design. Therefore, the participants were assigned randomly to four scenarios under manipulated conditions of knowledge and risk with 30 subjects each. More specifically, participants were instructed to imagine themselves in the situation described in the scenario.

Knowledge. This experiment used a procedure of manipulating knowledge introduced by several previous studies (Fabrigar et al., 2006) with some adjustments. The product label is a powerful medium for delivering messages, information and knowledge that compete to help determine consumer perceptions and the adoption of the new products (Roe and Teisl, 2007). Therefore, each participant in the high-knowledge groups was provided with 15 pieces of information about the quality standards, materials, ingredients, recipes, uses, and product benefits 
on the label of the product as well as the common ways to choose, store, and use general canned products (see Appendix). The participants in the low-knowledge groups were only provided with 5 pieces of information on the product.

Product risks. Previous studies indicate that information on risks involving using products affects consumers' perceived risk (Campbell and Goldstein, 2001; Gurhan-Canli and Batra, 2004). We adapted their procedures to manipulate the perceived risk. In the high-risk subgroups, the participants were told that this product was a new product at the stage of market testing and the quality and safety had not been certificated by the Food Safety Department. In addition, the participants were also told that the Food Safety Department reports that a considerable ratio of cases of risks occurring for consumers using general canned products come from products that are not clear in origin and are produced without a quality and safety certificate. By contrast, in the low-risk subgroups, the participants were told that this product was a new product, which had passed the stage of market testing and received a certificate of product quality and safety from the Food Safety Department. Our manipulation of risk is according to 'objective' food risks widely communicated by mass media that Vietnam has from 250 to 500 cases of food poisoning with more than 10.000 victims and approximately 200 fatalities per year ${ }^{1}$ and that most food products sold in the local markets are unbranded and without a safety certificate. It also reflects the fact that the bad habit of eating less carefully of most people in this market, such as having meals at 'pavement' or 'street' cafes, is very common.

\section{Questionnaire and measures}

We developed four questionnaires corresponding to four cells of the experiment (low versus high knowledge $\times$ low vs. high risk). Specifically, each participant was asked to read information

\footnotetext{
${ }^{1}$ Annual Report of the Ministry of Public Health (2007)
} 
about the product and information about how to choose, store, and use it, then answered some specific questions about the knowledge that he or she perceived. Next, each participant read a brief description containing the risk manipulation of the product, and was asked to evaluate his or her perceptions of risks regarding the product. The participants were then served the same meal with a canned mackerel and a piece of bread. After having the meal, the participants were asked to indicate their level of satisfaction feelings and their certainty for each corresponding item of satisfaction based on their sensory experience of the product. Finally, they were asked to rate their purchase intention and answer demographic questions. The items were identical for all versions of the questionnaire.

Perceived knowledge is measured with seven items: '(1) I understand fully about the ingredients of this product; (2) I understand fully about the nutritious value of this product; (3) I have enough information to evaluate the quality of this product; (4) I have enough knowledge to know whether this product is safe or not; (5) I have enough knowledge about how to choose this product correctly; (6) I have enough knowledge about how to store this product correctly; (7) I have enough knowledge about how to prepare this product for my meals' (alpha $=0.85$ ) $($ Pieniak et al., 2007).

Perceived risk is assessed by asking the respondents to indicate their evaluations on six aspects of perceived risk (performance, functional, financial, health, psychological, and social) (Jacoby and Kaplan ,1972; Yuksel and Yuksel, 2007) on a seven-point Likert scale as follows: 'If I buy this product: (1) I am afraid that it will not as taste as I want; (2) I am worried that it does not fulfil the standards of quality; (3) I am afraid that I will lose money for doing it; (4) I am afraid that this product will harm my health; (5) I think that buying it will make me uncomfortable; and (6) I think that my family (friends/roommates) will refuse to eat it' (alpha = 0.77). 
The respondents were asked to indicate the level of their satisfaction on a seven-point semantic differential scale with four items in the form: 'Compared with my expectances about the product, when I eat it, I feel': (1) Unpleasant/Pleasant, (2) Dissatisfied/Satisfied, (3) Dull/Exciting; and (4) Bored/Enjoyable (alpha = 0.90) (Oliver, 1980; Tuu and Olsen, 2009).

Perceived certainty has usually been measured by asking people how certain or how confident they are about their satisfaction judgments regarding the evaluated object (Yi and La, 2003). This study measures perceived certainty so that each evaluation on a multi-item scale of satisfaction in the left column corresponds with one item in the right column in the form: 'How confident do you feel about your evaluation of these items: (1) Totally unconfident/(7) Totally confident' $($ alpha $=0.93)$.

Intention to purchase this product is assessed using two items on a semantic seven-point scale in the form: 'How likely is it that you will buy or choose to eat this product again if it is available in the market during the next month with a given price unit of 7.500 VND': (1) The probability for me to buy/eat this product; (2) I expect to buy/eat this product: $1=$ Very unlikely to $7=$ Very likely’ (alpha $=0.88)($ Johnson et al., 2006).

The reliability and validity of the measures of these five constructs were evaluated by a confirmatory factor analysis and the results support the appropriate psychological characteristics of the measures of the intended constructs ${ }^{2}$ (Anderson and Gerbing, 1988).

\section{Analytical results}

\section{Manipulation and randomization checks}

\footnotetext{
${ }^{2}$ Fit statistics: $\chi^{2}=168.5, d f=121, p=0.003$; RMSEA $=0.06$; GFI $=0.87$; CFI $=0.97$. All the composite reliabilities exceed the minimum value of 0.60 and the individual item loadings on the constructs are all highly significant $(p<0.001: t$-value $>5)$ with values ranging from 0.63 to 0.97 .
} 
First, the average scores of the measures of perceived knowledge and risk were counted to generate the composite indicators of corresponding constructs. Next, an ANOVA was run on each composite indicator of perceived knowledge and risk to determine whether these measures differed in the subgroups. There was a significant difference between the two knowledge subgroups $($ low mean $=4.32$ versus high mean $=5.15, \mathrm{~F}(1,118)=25.7, \mathrm{p}<0.001)$. Similarly, risk manipulation succeeded in creating the appropriate differences in perceived risk between low- and high-risk conditions (low mean $=3.33$ versus high mean $=4.08, \mathrm{~F}(1,118)=23.6, \mathrm{p}<$ 0.001). In addition, as suggested by Purdue and Summers (1986), the manipulation check analysis should address whether the knowledge manipulation impacts on risk perceptions or whether the risk manipulation affects the perceived knowledge. The analytical results indicate that there are no differences in perceived risk between the knowledge groups (mean difference $=$ $0.21, \mathrm{~F}(1,118)=1.53, \mathrm{p}>0.10)$ as well as no differences in perceived knowledge between the risk groups $($ mean difference $=0.27, \mathrm{~F}(1,118)=2.21, \mathrm{p}>0.10)$. Therefore, the manipulations of product risk and knowledge are independent from each other.

Randomization checks were conducted to ensure that random assignment resulted in the equal distribution of subject characteristics. ANOVA was used for the variables of age and sex across the manipulated conditions of risk and knowledge. No significant differences between groups were found for age and gender with all the $\mathrm{p}$-values greater than 0.10 . These tests give assurance that the observed differences (if any) in the dependent variable measures are due to the stimulus manipulations rather than uncontrolled factors.

\section{Testing the hypotheses}

Our theoretical hypotheses include both direct and moderator effects. The experimental design contains independent variables in both types of manipulation (i.e., risk and knowledge) and 
measure (i.e., satisfaction and certainty). Thus, we use different approaches to test the hypotheses. Specifically, concerning the effects of measured variables of certainty and satisfaction on purchase intention, a moderated regression analysis is applied (Cohen and Cohen, 1983). However, the direct effects of manipulated risk and knowledge as well as of their interaction on satisfaction, purchase intention and certainty are analysed by using ANOVAs. The moderator effects of both manipulated risk and knowledge on the satisfaction-purchase relationship are tested through analysing the consistence of this relationship by comparing correlations and unstandardized regression coefficients between the subgroups (Baron and Kenny, 1986; Cohen and Cohen, 1983). Finally, a general linear model (two-way ANOVA) is used to test the interaction effect between manipulated risk and knowledge affecting satisfaction, purchase intention, certainty and the satisfaction-purchase intention relationship. Table 1 summarizes the contents of the theoretical hypotheses and their test results.

\section{Table 1 about here}

The results of the regression analysis ${ }^{3}$ support Hypothesis 1 by indicating that satisfaction has a significant positive main effect on purchase intention $(b=0.60, t=8.2, p<0.001)$. This result is important and necessary for testing further moderating effects on this relationship.

The results show a positive effect of certainty on purchase intention, but it is not significant (b $=0.05, \mathrm{t}=0.7, \mathrm{p}>0.10)$, thus Hypothesis $2 \mathrm{a}$ is not supported. However, the interaction between satisfaction and certainty has a positive effect on purchase intention $(b=0.12, t=2.5, p<0.05)$, which indicates a positive moderator effect of certainty on the satisfaction-purchase intention relationship. This means that Hypothesis $2 \mathrm{~b}$ is supported.

\footnotetext{
${ }^{3}$ Purchase intention $=3.48+0.60$ Satisfaction +0.05 Certainty +0.12 Satisfaction $\times$ Certainty

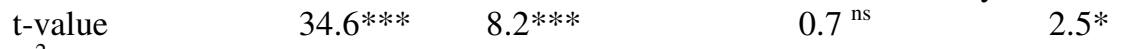
$\mathrm{R}^{2}=0.42 ; \mathrm{F}(3,116)=28.2, \mathrm{p}<0.001$.
} 
Hypothesis 3 proposed that higher manipulated risk decreased satisfaction (3a), purchase intention (3b), and certainty (3c). An ANOVA was used with manipulated risk is as a dichotomy variable receiving the value of 1 for the consumers in high-risk conditions and the value of 0 for the others. The results do not support Hypothesis 3a by showing that the difference in the evaluation of satisfaction between the respondents of the low-risk groups and those of the highrisk groups is not significant $\left(\mathrm{MS}_{\text {low-risk }}=3.76\right.$ vs. $\left.\mathrm{MS}_{\text {high-risk }}=3.92, \mathrm{~F}(1,118)=0.4, \mathrm{p}>0.10\right)$. However, the respondents in the low-risk condition reported their purchase intention to be significantly higher relative to the respondents in the high-risk condition $\left(\mathrm{MI}_{\text {low-risk }}=3.64 \mathrm{vs}\right.$. MI high-risk $=3.18, \mathrm{~F}(1,118)=3.2, \mathrm{p}<0.10)$. The certainty of the respondents in the low-risk condition is also significantly higher than one of the respondents in the high-risk condition (MC low-risk $=5.17$ vs. $\left.\mathrm{MC}_{\text {high-risk }}=4.74, \mathrm{~F}(1,118)=2.8, \mathrm{p}<0.10\right)$. These results mean that Hypotheses $3 \mathrm{~b}$ and $3 \mathrm{c}$ are supported.

Hypothesis $3 \mathrm{~d}$ proposed that higher manipulated risk would lead to lower consistence in the satisfaction-purchase intention relationship. This calls for a higher correlation between satisfaction and purchase intention in the low-risk groups relative to high-risk groups. The results show that the correlation between satisfaction and purchase intention in the low-risk groups differs significantly from zero $\left[\mathrm{R}_{\mathrm{LR}}(60)=0.74\right.$; Fisher's transformed $\mathrm{z}=0.95 ; \mathrm{SD}_{\mathrm{z}}=0.13, \mathrm{t}=$ 7.2, $\mathrm{p}<0.001)]$, and is significantly higher than the correlation $\left[\mathrm{R}_{\mathrm{HR}}(60)=0.54\right.$; Fisher's transformed $\left.\left.\mathrm{z}=0.60 ; \mathrm{SD}_{\mathrm{z}}=0.13, \mathrm{t}=4.5, \mathrm{p}<0.01\right)\right]$ in the high-risk groups $(\mathrm{z}=1.9, \mathrm{p}<0.10)$. The variances of the satisfaction measure did not differ significantly between the low-risk groups $(\mathrm{SD}=1.34)$ and the high-risk groups $(\mathrm{SD}=1.47)[\mathrm{F}(1,118)=0.4, \mathrm{p}=0.54]$. Thus, it cannot be assumed that a comparison of the zero-order correlations of the low-versus high-risk conditions is compromised by a restricted satisfaction range in the high-risk groups (Cohen and Cohen, 1983). However, it is desirable to compare the unstandardized regression coefficients, since this 
analysis is robust regarding the heterogeneity of variances (Baron and Kenny, 1986; Cohen and Cohen, 1983; see also Jonas et al., 1997 for a similar application). These coefficients represent the effect of satisfaction on purchase intention with respect to the two levels of the risk manipulation. The unstandardized regression coefficient is $b=0.78$ in the low-risk groups and $b$ $=0.52$ in the high-risk groups. These two coefficients differ significantly from each other $(\mathrm{t}=-$ $1.8, \mathrm{p}<0.10)$. These findings support a negative moderation effect of manipulated risk on the satisfaction-purchase intention relationship (Hypothesis 3d).

Hypothesis 4 suggested that higher manipulated knowledge increased satisfaction (4a), purchase intention (4b) and certainty (4c). Similarly, an ANOVA was used with manipulated knowledge is as a dichotomy variable receiving the value of 1 for the consumers in highknowledge conditions and the value of 0 for the others. The results show that the satisfaction level of the respondents in the low-knowledge groups is not significantly different from that of the respondents in the high-risk groups $\left(\mathrm{MS}_{\text {low-knowledge }}=3.97\right.$ vs. $\mathrm{MS}_{\text {high-knowledge }}=3.71, \mathrm{~F}(1$, $118)=1.1, \mathrm{p}>0.10)$. Therefore, Hypothesis $4 \mathrm{a}$ is not supported. However, the respondents in the high-knowledge condition reported their purchase intention as significantly higher relative to the respondents in the low-knowledge condition $\left(\mathrm{MI}_{\text {low-knowledge }}=3.18 \mathrm{vs} . \mathrm{MI}_{\text {high-knowledge }}=3.65, \mathrm{~F}\right.$ $(1,118)=3.4, p<0.10)$. The certainty of the respondents in the high-knowledge condition is also significantly higher than that of the respondents in the low-knowledge condition ( $\mathrm{MC}_{\text {low-knowledge }}$ $=4.46$ vs. $\left.\mathrm{MC}_{\text {high-knowledge }}=5.45, \mathrm{~F}(1,118)=15.9, \mathrm{p}<0.001\right)$. Thus, Hypotheses $4 \mathrm{~b}$ and 4c are supported.

Hypothesis 4d suggested that higher manipulated knowledge would lead to a higher consistence in the satisfaction-purchase intention relationship. The computed correlation between satisfaction and purchase intention in the low-knowledge groups differs significantly from zero $\left[\mathrm{R}_{\mathrm{LK}}(60)=0.50 ;\right.$ Fisher's transformed $\left.\left.\mathrm{z}=0.55 ; \mathrm{SD}_{\mathrm{z}}=0.13, \mathrm{t}=4.1, \mathrm{p}<0.001\right)\right]$, but is 
significantly lower than the correlation $\left[\mathrm{R}_{\mathrm{HK}}(60)=0.80\right.$; Fisher's transformed $\mathrm{z}=1.10 ; \mathrm{SD}_{\mathrm{z}}=$ $0.13, \mathrm{t}=8.3, \mathrm{p}<0.001)]$ in the high-knowledge groups $(\mathrm{z}=2.9, \mathrm{p}<0.01)$. Because the variances of the satisfaction measure did not differ significantly between the low-knowledge groups $(\mathrm{SD}=$ 1.44) and the high-knowledge groups $(\mathrm{SD}=1.37)[\mathrm{F}(1,118)=0.4, \mathrm{p}=0.52]$, a comparison of unstandardized coefficients was conducted (Cohen and Cohen, 1983). The unstandardized regression coefficients in the low-knowledge versus high-knowledge groups are $b=0.48$ and $b=$ 0.84 , respectively. These two coefficients differ significantly from one another $(t=2.6, p<0.05)$. These results support a positive moderation effect of manipulated knowledge on the satisfactionpurchase intention relationship (Hypothesis 4d).

To test Hypotheses 5a, 5b and 5c, a two-way ANOVA was used with a model including manipulated risk and knowledge and an interaction between them as independent variables and satisfaction, purchase intention and certainty as dependent variables. The results do not support Hypotheses $5 \mathrm{a}, 5 \mathrm{~b}$ and $5 \mathrm{c}$ by showing that the interaction between manipulated knowledge and risk has no significant effect on satisfaction $[\mathrm{F}(1,116)=0.28, \mathrm{p}>0.10]$, purchase intention $[\mathrm{F}(1$, $116)=0.40, \mathrm{p}>0.10]$ and certainty $[\mathrm{F}(1,116)=2.1, \mathrm{p}>0.10]$.

Finally, to test Hypothesis 5d, a similar procedure to that used for testing Hypotheses $3 \mathrm{~d}$ and $4 \mathrm{~d}$ was used. However, the procedure was conducted separately for two conditions of low- versus high-manipulated knowledge. In the conditions of low-manipulated knowledge, the correlation between satisfaction and purchase intention in the low-risk groups differs significantly from zero $\left[\mathrm{R}_{\mathrm{LK}-\mathrm{LR}}(30)=0.71 ;\right.$ Fisher's transformed $\left.\left.\mathrm{z}=0.89 ; \mathrm{SD}_{\mathrm{z}}=0.19, \mathrm{t}=4.6, \mathrm{p}<0.001\right)\right]$, and is significantly higher than the correlation $\left[\mathrm{R}_{\mathrm{LK}-\mathrm{HR}}(30)=0.30\right.$; Fisher's transformed $\mathrm{z}=0.31 ; \mathrm{SD}_{\mathrm{z}}=$ $0.19, \mathrm{t}=1.61, \mathrm{p}>0.10]$ in the high-risk groups $(\mathrm{z}=2.1, \mathrm{p}<0.05)$. In the conditions of highmanipulated knowledge, the correlation between satisfaction and purchase intention in the lowrisk groups differs significantly from zero $\left[\mathrm{R}_{\mathrm{HK}-\mathrm{LR}}(30)=0.88\right.$; Fisher's transformed $\mathrm{z}=1.4 ; \mathrm{SD}_{\mathrm{z}}$ 
$=0.19, \mathrm{t}=7.1, \mathrm{p}<0.001)]$, but is not significantly higher than the correlation $\left[\mathrm{R}_{\mathrm{HK}-\mathrm{HR}}(30)=\right.$ 0.78; Fisher's transformed $\left.\mathrm{z}=1.04 ; \mathrm{SD}_{\mathrm{z}}=0.19, \mathrm{t}=5.4, \mathrm{p}<0.001\right]$ in the high-risk groups $(\mathrm{z}=$ 1.2, $\mathrm{p}>0.10)$. The results imply that while the negative moderator effect of risk on the satisfaction-purchase relationship is strong in the conditions of low-manipulated knowledge, it is weaker and not significant in the conditions of high-manipulated knowledge. Thus, this result reveals that higher manipulated knowledge moderates negatively the moderator effect of risk on the satisfaction-purchase intention relationship or that Hypothesis $5 \mathrm{~d}$ is supported. However, a further comparison of unstandardized coefficients indicates that in the conditions of lowmanipulated knowledge, the unstandardized regression coefficients in the low-risk versus highrisk groups are $b=0.64$ and $b=0.30$, respectively, but does not differ significantly from one another $(t=1.6, p>0.10)$. In the condition of high-manipulated knowledge, the unstandardized regression coefficients in the low-risk versus high-risk groups are $b=1.04$ and $b=0.70$, respectively, and differ significantly from one another $(\mathrm{t}=2.0, \mathrm{p}<0.10)$. This inconsistent result may come from a little difference in the variances of satisfaction between the compared subgroups $[\mathrm{F}(3,116)=1.3, \mathrm{p}=0.30]$. Therefore, although we find empirical evidence supporting Hypothesis 5d, it may be not robust enough.

\section{Discussions and implications}

This study conducts an experiment with 120 students in Vietnam to explore the effects of perceived certainty, manipulated risk and knowledge on satisfaction, purchase intention, and the satisfaction-purchase intention relationship in the context of a new product evaluation experiment with the possibility to perform a direct experience (sensory evaluation) with the products. The results prove the successfulness of manipulated conditions of product risks and knowledge as well as psychological characteristics of measures. Our study extends previous 
studies in the area of established products/brands (e.g., Capraro et al., 2003; Evanschitzky and Wunderlich, 2006; Tuu and Olsen, 2009) and brand extension (DelVecchio and Smith, 2005). Specifically, this study discusses and tests the different roles of perceived certainty, manipulated risk and knowledge on new-product satisfaction, intention to buy and especially the satisfactionpurchase intention relationship in a controlled experiment. Therefore, the findings contribute to providing a deeper understanding of the drivers and barriers, and their causal relationships, in moving from consumers' evaluation of satisfaction to purchase intention of new products.

\section{Theoretical findings and implications}

The present results confirm general marketing studies of a positive relationship between satisfaction and purchase intention (Johnson et al., 2006; Marzursky and Geva, 1989; Szymanski and Henard, 2001; Walsh et al., 2008). This means that an increase in customers' satisfaction will produce an equal increase in purchase intention. However, this does not mean that the effect of satisfaction on purchase intention is unchanged when the third variables are present. In this study, perceived certainty, manipulated risk and knowledge are introduced as such variables

(Chandrashekaran et al., 2007; Chiou et al., 2002; Gurhan-Canli and Batra, 2004; Tuu and Olsen, 2009).

Although perceived certainty in consumers' evaluation of their satisfaction with the new product does not affect purchase intention, it is first found to moderate positively the satisfaction-purchase intention relationship. Therefore, this study is one of a few studies (one exception is Chandrashekaran et al., 2007) that provide empirical support for the moderator role of certainty in the satisfaction literature (see Dick and Basu, 1994 for a conceptual discussion). At least for purchase intention in a new product setting, our findings suggest that a satisfied consumer is more likely to be vulnerable if he/she feels less certainty in their feelings of 
satisfaction. Thus, including perceived certainty in the evaluation of a new or established product or services may contribute to a deeper understanding of the probability to (re)purchase in the future. It is worthy noting that both manipulated risk and knowledge have proven to be important sources of certainty of satisfaction evaluations. Thus, this study extends Chandrashekaran et al.,'s (2007) study of certainty as an important satisfaction strength attribute by suggesting how certainty is related to other strength-related properties and risks.

This study expected to find a negative effect of manipulated risk on satisfaction, but our results indicate no significant relationship between these constructs. This finding is inconsistent with previous studies (Grewal et al., 2007; Tuu and Olsen, 2009) using a cross-sectional design (survey) and confirming a negative effect of perceived risk on consumers' satisfaction. The reason may be that the information on product risk may reduce both consumers' expectations (Bennett and Harrell, 1975; Oliver, 1980) and perceived performance (Alhakami and Slovic, 1994; Saba and Messina, 2002), which makes their satisfaction level ${ }^{4}$ unpredictable. In other words, the negative relationship between manipulated risk and satisfaction is unclear in a specific transaction. In addition, it is possible that the different aspects of product risk can contribute to no or different effects on its consequences including attitudes or satisfaction (Tsiros and Heilman, 2005). Furthermore, the association between risk and satisfaction may be an indirect rather than a direct effect (Yukel and Yuksel, 2007).

However, manipulated risk is found to relate negatively to purchase intention, which is consistent with previous studies' findings (Angulo and Gil, 2007; Grewal et al., 2007; Yuksel and Yuksel, 2007). Therefore, potential customers may not intend to buy a new product just because they know much risky information or perceive a high level of risks about the product. Our

\footnotetext{
${ }^{4}$ The formation of satisfaction is explained by the 'disconfirmation of expectations' model, which proposes that feelings of satisfaction arise when consumers compare their perceptions of a product's performance with their expectations (Oliver, 1980).
} 
findings show that risk can influence intention without influencing satisfaction, probably because risk is more closely associated with expectations about future consequences than an ultimate transaction-specific evaluation of new products, which does not automatically give any riskassociated consequences for the consumer.

Our experimental empirical evidence supports that manipulated risk acts as a negative moderator in the satisfaction-purchase intention relationship. A similar result is found when manipulated risk is defined as a moderator in the evaluation-choice/behaviour relationship (Campbell and Goldstein, 2001; Gurhan-Canli and Batra, 2004). In the area of brand extension, different aspects of manipulated product category risk have been proven to be an important positive moderators affecting the success of marketing a new product (DelVecchio and Smith, 2005). In this context, the reputation of the brand name from which the new product is extended plays an important role as a source of reducing category risks, and thus, generates advantages relative to competitors. In contrast with DelVecchio and Smith's study, when the brand name is not presented, product risk has been proven in this study to be a barrier to rather than a facilitator for marketing a new product. Thus, the consideration of the moderator effect of manipulated risk in this case provides a deeper insight into the mechanism of the formation of purchase intention from satisfaction by suggesting that satisfaction may fail to predict purchase intention under highly risky situations in the context of new products.

The findings show that higher manipulated knowledge leads to a higher purchase intention towards the product. Our finding is consistent with most previous studies (Rortveit and Olsen, 2007; Soderlund, 2002) even though some studies also report no effect of knowledge on (re)purchase intention (Bell et al., 2005). However, manipulated knowledge did not influence consumers' satisfaction with the product in this study. This result is inconsistent with previous studies suggesting that consumers with higher knowledge would have more positive attitude 
evaluation (Chen and Li, 2007; Cordell, 1997) or a higher level of satisfaction with the products (Tuu and Olsen, 2009) than those with lower knowledge. The reason may be that in their studies, knowledge has been measured rather than experimentally manipulated. Thus, it is difficult to decompose knowledge effects from other variables with which this construct is correlated, such as attitude certainty, extremity, and accessibility (Fabrigar et al., 2006). In addition, knowledge and expertise in cross-sectional surveys do not control for the possibility that repeated experiences with the products consumers buy, consume, and are satisfied with influence consumer knowledge of the products (Alba and Hutchinson, 1987; Park et al., 1994). This issue makes correlations between consumption/satisfaction and knowledge increase as a function of repeated action over time. Therefore, the causal relationship in our experiment may be more robust than in several cross-sectional studies where knowledge, expertise, attitudes/satisfaction, and intention/choice are measured at the same time in a survey context (Capraro et al., 2003; Chen and Li, 2007; Evanschitzky and Wunderlich, 2006; Tuu and Olsen, 2009).

Manipulated knowledge is in our results suggested to be a positive moderator in the satisfaction-purchase intention relationship. This means that knowledge can play an important role in narrowing the gap between satisfaction and purchase intention. Our results are consistent with the viewpoint of Chiou et al., 2002), and are supported in the more general theory of knowledge as a moderator in the attitude-behaviour relationship (Fabrigar et al., 2006). However, our findings oppose some previous studies on marketing that find a negative moderating effect of perceived knowledge on the satisfaction-loyalty relationship (Capraro et al., 2003; Evanschitzky and Wunderlich, 2006; Tuu and Olsen, 2009). It is also worthy of note that this study suggests the first empirical evidence supporting an interacting effect of manipulated knowledge and risk affecting the satisfaction-purchase intention relationship. The finding is consistent with most previous studies suggesting that educating consumers with relevant knowledge is an important 
marketing strategy to reduce consumers' potential risks as well as their negative effects (Chen and Li, 2007; Gurhan et al., 2004; Tuu and Olsen, 2009). Our findings are thus important and contribute to making clearer the complex and causal role of consumer knowledge in the movement from consumer satisfaction to purchase intention towards new products.

\section{Managerial implications and limitations}

This study has several managerial implications. First, the marketing literature in the area of customer management has confirmed that satisfaction is considered as a vital strategy for companies (Anderson and Sullivan, 1993) as well as for marketing new products (Johnson et al., 2006). However, it is common that it is difficult for a new product to obtain high levels of consumer satisfaction in the first stage of its life (Cooper and Kleinschmidt, 1991). Thus, it may be that a marketing strategy decreasing consumers' expectations along with providing excessive performance in this stage is appropriate (Oliver, 1980). Second, this study indicates that improving consumer satisfaction may be not sufficient to increase purchase intention, especially in high-risk situations. Thus, to enhance consumers' purchase intention, management attention should focus on risk-reducing strategies for customers (Angulo and Gil, 2007; Tuu and Olsen 2009; Yuksel and Yuksel, 2007). Quality control and giving consumers a quality guarantee when buying a fish product are two possible strategies (Angulo and Gil, 2007). Third, our findings also indicate that satisfied consumers with higher relevant knowledge about new products show a higher ability to purchase them; thus, increasing consumer knowledge in the first stages of the products' life may be an appropriate strategy for marketing them successfully. It is also the case that a label is designed with full information about the product's attributes as well as use guides can generate important advantages increasing consumers' trust and confidence and their acceptance of the new product (Roe and Teisl, 2007). Finally, consistent with previous studies 
that call for an insight to explain and understand the complex mechanism of consumer satisfaction (Chandrashekaran et al., 2007), this study suggests that managers and marketers should not only understand the levels of their customers' satisfaction, but also understand its certainty in their evaluative process.

Despite the above contributions, this study has several limitations. First, the study has not considered the different moderators of the satisfaction-purchase intention relationship such as consumer or situational characteristics (Evanschitzky and Wunderlich, 2006). Second, this study uses only one new food product. Future studies should extend the model to include more moderators as well as use an experimental design with a variety of new different products, brands and services to gain a more comprehensive understanding of the formation of purchase intentions. Third, product risk consists of multidimensional constructs including many facets (Jacoby and Kaplan, 1972; Yuksel and Yuksel, 2007), but in this study, we manipulated product risks as an overall construct. Even though our manipulation of risk influenced an integrated measure of perceived risk, the different effects of the facets of product risk are not easy to distinguish. It will be interesting for future studies to manipulate each of the facets of product risk, such as financial risk, to explore their effects on consumer satisfaction and purchase intentions as well as the relationship between these two constructs (DelVecchio and Smith, 2005). Finally, knowledge also has several facets and dimensions (Alba and Hutchinson, 1987; Park et al., 1994; Worsley, 2002). The different dimensions of knowledge have been shown to have unequal effects on different outcome variables (Cordell, 1997; Park et al., 1994; Rortveit and Olsen, 2007). Our manipulation of knowledge focuses more on declarative and general knowledge about a new product. Thus, future studies would benefit from manipulating procedural knowledge, which may be important for intervention programmes as well as the marketing of new products. 


\title{
References
}

\author{
Alba, J.W. and Hutchinson, J.W. (1987), “Dimensions of consumer expertise”, Journal of \\ Consumer Research, Vol. 13 No. 4, pp. 411-454.
}

Alhakami, A.S. and Slovic, P. (1994), “A psychological study of the inverse relationship between perceived risk and perceived benefit”, Risk Analysis, Vol. 14 No. 6, pp. 1085-1096.

Anderson, E.W. and Sullivan, M.W. (1993), “The antecedents and consequences of customer transaction satisfaction for firms", Marketing Science, Vol. 12 No. 2, pp. 125-143.

Anderson, J.C. and Gerbing, D.W. (1988), "Structural equation modelling in practice: A review and recommended two step approach", Psychological Bulletin, Vol. 103 No. 3, pp. 411-423.

Angulo, A.M. and Gil, J.M. (2007), "Risk perception and consumer willingness to pay for certified beef in Spain”, Food Quality and Preference, Vol. 18 No. 8, pp. 1106-1117.

Baron, R.M. and Kenny, D.A. (1986), “The moderator-mediator variable distinction in social psychological research: Conceptual, strategic, and statistical considerations", Journal of Personality and Social Psychology, Vol. 51 No. 6, pp. 1173-1182.

Bauer, R.A. (1960), “Consumer behavior as risk taking”, In R. L. Hancock (Ed.), Dynamic marketing for a changing world. Chicago: American Marketing Association.

Bell, S.J., Auh, S. and Smalley, K. (2005), “Customer relationship dynamics: Service quality and customer loyalty in the context of varying levels of customer expertise and switching costs", Journal of the Academy of Marketing Science, Vol. 33 No. 2, pp. 169-183.

Bennett, P.D. and Harrell, G.D. (1975), “An evaluation of the expectance/value model of attitude measurement for physical prescribing behavior", Marketing Research, Vol. 11 No. 3, pp. 269-278. 
Berger, I.E. (1992), “The nature of attitude accessibility and attitude confidence: A triangulated experiment", Journal of Consumer Psychology, Vol. 1 No. 2, pp. 103-123.

Berger, I.E., Ratchford, B.T. and Haines, G.H.Jr. (1994), “Subjective product knowledge as a moderator of the relationship between attitudes and purchase intentions for a durable product”, Journal of Economic Psychology, Vol. 15, pp. 301-314.

Campbell, M.C. and Goldstein, R.C. (2001), “The moderating effect of perceived risk on consumers' evaluations of product incongruity: Preference for the norm”, Journal of Consumer Research, Vol. 28 No. 3, pp. 439-449.

Campbell, W.K., Goodie, A.S. and Foster, J.D. (2004), "Narcissism, confidence, and risk attitude", Journal of Behavioral Decision Making, Vol. 17 No. 4, pp. 297-311.

Caporale, G. and Monteleon, E. (2004), "Influence of information about manufacturing process on beer acceptability", Food Quality and Preference, Vol. 15 No. 3, pp. 271-278.

Capraro, A.J., Broniarczyk, S. and Srivastava, R.K. (2003), "Factors influencing the likelihood of customer defection: The role of consumer knowledge", Journal of the Academy of Marketing Science, Vol. 31 No. 2, pp. 164-175.

Chandrashekaran, M., Rotte, K., Tax, S.S. and Grewal, R. (2007), "Satisfaction strength and customer loyalty”, Journal of Marketing Research, Vol. 44 No. 1, pp. 153-163.

Chen, M.F. and Li, H.L. (2007), “The consumer's attitude toward genetically modified foods in Taiwan”, Food Quality and Preference, Vol. 18 No. 4, pp. 662-674.

Chiou, J.S., Droge, C. and Hanvanich, S. (2002), "Does customer knowledge affect how loyalty is formed?", Journal of Service Research, Vol. 5 No. 2, pp. 113-124.

Cohen, J. and Cohen, P. (1983), Applied multiple regression/correlation analysis for the behavioral sciences, Hillsdale, NJ: Erlbaum. 
Cooper, R.G. and Kleinschmidt, E.J. (1987), “New products: What separates winners from losers?", Journal Product Innovation Management, Vol. 4 No. 3, pp. 169-184.

Cooper, R.G. and Kleinschmidt, E.J. (1991), "New product processes at leading industrial firms", Industrial Marketing Management, Vol. 20 No. 2, pp. 137-147.

Cordell, V.V. (1997), “Consumer knowledge measures as predictors in product evaluation”, Psychology and Marketing, Vol. 14 No. 3, pp. 241-260.

DelVecchio, D. and Smith, D.C. (2005), "Brand-extension price premium: The effects of perceived fit and extension product category risk", Journal of the Academy of Marketing Science, Vol. 33 No. 2, pp. 184-196.

Dick, A.S. and Basu, K. (1994), “Customer loyalty: Toward an integrated conceptual framework", Journal of the Academy of Marketing Science, Vol. 22 No. 2, pp. 99-113.

Dowling, G.R. (1986), “Perceived risk: the concept and its measurement”, Psychology and Marketing, Vol. 3 No. 3, pp. 193-210.

Dowling, G.R. and Staelin, R. (1994), “A model of perceived risk and intended risk-handling activities", Journal of Consumer Research, Vol. 21 June, pp. 119-134.

Evanschitzky, H. and Wunderlich, M. (2006), “An examination of moderator effects in the fourstage loyalty model”, Journal of Service Research, Vol. 8 No. 4, 330-345.

Fabrigar, L.R., Petty, R.E., Smith, S.M. and Crites, S.L.Jr. (2006), “Understanding knowledge effects on attitude-behavior consistency: The role of relevance, complexity, and amount of knowledge", Journal of Personality and Social Psychology, Vol. 90 No. 4, pp. 556-577.

Gardial, S.F., Clemons, D.S., Woodruff, R.B., Schumann, D.W. and Burns, M.J. (1994), “Comparing consumers' recall of prepurchase and postpurchase product evaluation experiences", Journal of Consumer Research, Vol. 20 No. 2, pp. 548-560. 
Grewal, D., Iyer, G.R., Gotlieb, J. and Levy, M. (2007), "Developing a deeper understanding of post-purchase perceived risk and behavioural intentions in a service setting", Journal of the Academy of Marketing Science, Vol. 35 No. 2, pp. 250-258.

Gurhan-Canli, Z. and Batra, R. (2004), "When corporate image affects product evaluations: The moderating role of perceived risk", Journal of Marketing Research, Vol. 41 No. 2, pp. 197205.

Heilman, C.M., Bowman, D. and Wright, G.P. (2000), "The evolution of brand preferences and choice behaviors of consumers new to a market", Journal of Marketing Research, Vol. 37 No. 2, pp. 139-155.

Jacoby, J. and Kaplan, L.B. (1972), “The components of perceived risk”, In M. Venkatesan (Ed.), Proceedings of the third annual conference of the Association for Consumer Research (pp. 382-393). Iowa City, IA: Association for Consumer Research.

Johnson, M.D., Herrmann, A. and Huber, F. (2006), “The evolution of loyalty intention”, Journal of Marketing, Vol. 70 No. 2, pp. 122-132.

Johnson, M.D., Nader, G. and Fornell, C. (1996), “Expectations, perceived performance, and customer satisfaction for a complex service: The case of bank loans", Journal of Economic Psychology, Vol. 17 No. 2, pp. 163-182.

Jonas, K., Diehl, M. and Broemer, P. (1997), "Effects of attitudinal ambivalence on information processing and attitude-intention consistency”, Journal of Experimental Social Psychology, Vol. 33, pp.190-210.

Laroche, M., Kim, C. and Zhou, L. (1996), "Brand familiarity and confidence as determinants of purchase intention: An empirical test in a multiple brand context", Journal of Business Research, Vol. 37 No. 10, pp. 115-120. 
Lim, N. (2003), “Consumers’ perceived risk: Sources versus consequences”, Electronic Commerce Research and Applications, Vol. 2 No. 3, pp. 216-228.

Martinez-Poveda, A, Molla-Bauza, M.B., del Campo-Gomis, F.J. and Martinez, L.M.C. (2009), "Consumer-perceived risk model for the introduction of genetically modified food in Spain", Food Policy, Vol. 34 No. 6, pp. 519-528.

Mazursky, D. and Geva, A. (1989), “Temporal decay in satisfaction-purchase intention relationship", Psychology and Marketing, Vol. 6 No 3, pp. 211-226.

Mitchell, V., Davies, F., Moutinho, L. and Vassos, V. (1999), “Using neural networks to understand service risk in the holiday product", Journal of Business Research, Vol. 46 No. 2 , pp. 167-180.

Mittal, V. and Kamakura, W.A. (2001), "Satisfaction, repurchase intent, and repurchase behavior: Investigating the moderating effect of customer characteristics", Journal of Marketing Research, Vol. 38 No. 1, pp. 131-142.

Oliver, R.L. (1980), “A cognitive model of the antecedents and consequences of satisfaction decisions", Journal of Marketing Research, Vol. 17 No. 4, pp. 460-69.

Oliver, R.L. (1997), Satisfaction: A behavioral perspective on the consumer, New York: Irwin/McGraw-Hill.

Olsen, S.O. (1999), "Strength and conflicting valence in the measurement of food attitudes and preferences”, Food Quality and Preference, Vol. 10 No. 6, pp. 483-494.

Park, W., Mothersbaugh, D.L and Feick, L. (1994), "Consumer knowledge assessment”, The Journal of Consumer Research, Vol. 21 No. 1, pp. 71-82.

Pieniak, Z., Verbeke, W., Scholderer, J.I., Brunso, K. And Olsen, S.O. (2007), European consumers' use of and trust in information sources about fish", Food Quality and Preference, Vol. 18, pp. 1050-1063. 
Pires, G., Stanton, J. and Eckford, A. (2006), "Influences on the perceived risk of purchasing online", Journal of Consumer Behaviour, Vol. 4 No. 2, pp. 118-131.

Perdue, B.C. and Summers, J.O. (1986), “Checking the success of manipulations in marketing experiments", Journal of Marketing Research, Vol. 23 No. 4, pp. 317-326.

Roe, B. and Teisl, M.F. (2007), "Genetically modified food labeling: The impacts of message and messenger on consumer perceptions of labels and products", Food Policy, Vol. 32 No. 1, pp. 49-66.

Rortveit, A.W. and Olsen, S.O. (2007), “The role of consideration set size in explaining fish consumption”, Appetite, Vol. 49 No. 1, pp. 214-222.

Saba, A and Messina, F. (2002), “Attitudes towards organic foods and risk/benefit perception associated with pesticides", Food Quality and Preference, Vol. 14 No. 8, pp. 637-645.

Seiders, K., Voss, G.B., Grewal, D. and Godfrey, A.L. (2005), "Do satisfied customers buy more? Examining moderating influences in a retailing context”, Journal of Marketing, Vol. 69 No. 4, pp. 26-43.

Smith, S.M, Fabbrigar, L.R., MacDougall, B.L. and Wiesenthal, N.L. (2008), “The role of amount, cognitive elaboration, and structural consistency of attitude-relevant knowledge in the formation of attitude certainty”, European Journal of Social Psychology, Vol. 38, pp. 280-295.

Smith, R.E. and Swinyard, W.R. (1983), “Attitude-behavior consistency: The impact of product trial versus advertising”, Journal of Marketing Research, Vol. 20 No. 3, pp. 257-267.

Soderlund, M. (2002), "Customer familiarity and its effects on satisfaction and behavioral intentions", Psychology and Marketing, Vol. 19 No. 10, pp. 861-879.

Spreng, R.A, MacKenzie, S.B. and Olshavsky, R.W. (1996), “A re-examination of the determinants of consumer satisfaction", Journal of Marketing, Vol. 60 No. 3, pp. 15-32. 
Szymanski, D.M. and Henard, D.H. (2001), "Customer satisfaction: A meta-analysis of the empirical evidence”, Journal of the Academy of Marketing Science, Vol. 29 No. 1, pp. 16-35.

Tsiotsou, R. (2006), “The role of perceived product quality and overall satisfaction on purchase intentions", International Journal of Consumer Studies, Vol. 30 No. 2, pp. 207-217.

Tsiros, M. and Heilman, C.M. (2005), “The effect of expiration dates and perceived risk in purchasing behavior in grocery store perishable categories”, Journal of Marketing, Vol. 69 No. 2, pp. 114-129.

Tuu, H.H. and Olsen, S.O. (2009), "Food risk and knowledge in the satisfaction-loyalty relationship", Asia Pacific Journal of Marketing and Logistics, Vol. 21 No. 4, pp. 521-536.

Walsh, G., Evanschitzky, H. and Wunderlich, M. (2008), "Identification and analysis of moderator variables: Investigating the customer satisfaction-loyalty link", European Journal of Marketing, Vol. 42 No. 9/10, pp. 977-1004.

Worsley, A. (2002), "Nutrition knowledge and food consumption: Can nutrition knowledge change food behaviour?", Asia Pacific Journal of Clinical Nutrition, Vol. 11 No. 3, pp. 579585.

Yi, Y. and La, S. (2003), "The moderating role of confidence in expectations and the asymmetric influence of disconfirmation on customer satisfaction”, The Service Industry Journal, Vol. 23 No. 5, pp. 20-47.

Yuksel, A. and Yuksel, F. (2007), ’Shopping risk perception: Effects on tourists' emotion, satisfaction and expressed loyalty intentions", Tourism Management, Vol. 28 No. 3, pp. 703713. 
Appendix: The four scenarios

Scenario 1: High-knowledge and high-risk scenario

In front of you is a new product of a seafood company: canned mackerel. The information about this product is as follows:

\begin{tabular}{|c|c|c|c|c|c|}
\hline \multicolumn{6}{|c|}{ FRIED MACKEREL IN CHILI SAUCE } \\
\hline Net weight & \multicolumn{5}{|c|}{$170 \mathrm{~g}$} \\
\hline \multicolumn{6}{|l|}{ Ingredients } \\
\hline Fried mackerel & 60.0 & $\%$ & Vinegar & 3.0 & $\%$ \\
\hline Chili sauce & 27.0 & $\%$ & Chili & 2.8 & $\%$ \\
\hline Sugar & 4.6 & $\%$ & Salt & 1.0 & $\%$ \\
\hline Vegetable oil & 1.4 & $\%$ & Seasoning & 0.2 & $\%$ \\
\hline Nutritional value & & & & & \\
\hline Total value & \multicolumn{5}{|c|}{$140 \mathrm{kcal}$} \\
\hline American standard & & \multicolumn{4}{|c|}{$\begin{array}{l}\text { Percentages }(\%) \text { of a daily nutritional value are based on a } \\
2000 \text { calorie diet with total carbohydrate of } 160 \mathrm{~g}\end{array}$} \\
\hline Preserve & \multicolumn{5}{|c|}{ Keep in room temperature } \\
\hline Usage & \multicolumn{5}{|c|}{ Ready to eat - cold or hot, or process into other dishes } \\
\hline
\end{tabular}

The follows are general knowledge about how to choose, store, and use canned products to acquire a high-quality canned product: You should choose a canned product with a deep-set and unstained cover. You should buy a canned product with full information, such as mark, origin, quantity, quality standards, produced and expiration dates, and so on. The canned products must be stored in airy and dry places. Canned products are often used for eating instantly; however, you can reprocess them in your own ways, such as frying with tomato, with onion, with fish sauce, and the like. Please indicate ... (knowledge measures).

This product was a new product at the stage of market testing and the quality and safety had not been certificated by the Food Safety Department. Also, note that this Department reported that a considerable ratio of cases of risks occurring for consumers using canned products come from products that are not clear in origin and are produced without a quality and safety certificate. Please indicate ... (perceived risk measures)

Scenario 2: High-knowledge and low-risk scenario 
The identical text and table as the first scenario were used, except that one new sentence was used to manipulate the low-risk condition: 'This product was a new product but passed the stage of market testing and received a certificate of product quality and safety from the Food Safety Department'.

Scenario 3: Low-knowledge and high-risk scenario

The identical text as the first scenario was used, but information about this product is as follows:

\begin{tabular}{|lrl|}
\hline \multicolumn{2}{|l|}{ FRIED MACKEREL IN CHILI SAUCE } \\
Net weight & $\mathbf{1 7 0} \mathrm{g}$ \\
Ingredients & & \\
Fried mackerel & $\mathbf{6 0 . 0}$ & $\%$ \\
Different ingredients & $\mathbf{4 0 . 0} \%$ \\
Nutritional value & & \\
Total value & $\mathbf{1 4 0}$ kcal \\
Usage & Ready to eat \\
\hline
\end{tabular}

Scenario 4: Low-knowledge and low-risk scenario

The information about the product is similar to the scenario 3, but the information of product risk is from the scenario 2 . 


\section{Table 1.}

Results of testing the hypotheses

\begin{tabular}{clc}
\hline Hypotheses & \multicolumn{1}{c}{ Content } & Conclusion \\
\hline H1 & Satisfaction has a positive effect on purchase intention (PI) & Supported \\
H2a & Certainty has a positive effect on PI & Not supported \\
H2b & Certainty moderates positively the satisfaction-PI relationship & Supported \\
H3a & Risk has a negative effect on satisfaction & Not supported \\
H3b & Risk has a negative effect on PI & Supported \\
H3c & Risk has a negative effect on certainty & Supported \\
H3d & Risk moderates negatively the satisfaction-PI relationship & Supported \\
H4a & Knowledge has a positive effect on satisfaction & Not supported \\
H4b & Knowledge has a positive effect on PI & Supported \\
H4c & Knowledge has a positive effect on certainty & Supported \\
H4d & Knowledge moderates positively the satisfaction-PI relationship & Supported \\
H5a & Knowledge moderates negatively the risk- satisfaction relationship & Not supported \\
H5b & Knowledge moderates negatively the risk-PI relationship & Not supported \\
H5c & Knowledge moderates negatively the risk-certainty relationship & Not supported \\
H5d & Knowledge moderates negatively the moderator effect of risk on the & Supported \\
\hline
\end{tabular}





\section{APPENDIX - PAPER 5:}

\section{DESCRIPTIVE STATISTICS}

\begin{tabular}{lccccc}
\hline Constructs and indicators & Mean & $\begin{array}{c}\text { Std. } \\
\text { Dev. }\end{array}$ & $\begin{array}{c}\text { Skew- } \\
\text { ness }\end{array}$ & Kurtosis & $\mathrm{N}$ \\
\hline Satisfaction & 3.85 & 1.72 & -0.04 & -0.87 & 120 \\
Unpleasant/Pleasant & 3.98 & 1.62 & -0.18 & -0.94 & 120 \\
Unsatisfied/Satisfied & 3.86 & 1.55 & -0.10 & -0.99 & 120 \\
Dull/Exciting & 3.67 & 1.50 & -0.05 & -0.37 & 120 \\
Bored/Enjoyable & & & & & \\
Certainty & 4.88 & 1.67 & -0.75 & -0.40 & 120 \\
Certainty - Unpleasant/Pleasant & 5.03 & 1.67 & -0.76 & -0.20 & 120 \\
Certainty - Unsatisfied/Satisfied & 5.04 & 1.64 & -0.81 & -0.37 & 120 \\
Certainty - Dull/Exciting & 4.86 & 1.65 & -0.80 & -0.09 & 120 \\
Certainty - Dull/ Bored/Enjoyable & & & & & \\
Purchase intention & 3.47 & 1.49 & 0.18 & -0.88 & 120 \\
I expect to buy & 3.43 & 1.46 & 0.20 & -0.77 & 120 \\
The probability to buy & & & & & \\
\hline
\end{tabular}

